\title{
Complete genomic characteristics and pathogenic analysis of the newly emerged classical swine fever virus in China
}

\author{
Hongliang Zhang ${ }^{1 \dagger}$, Chaoliang Leng ${ }^{2 \dagger}$, Zhijun Tian ${ }^{1 \dagger}$, Chunxiao Liu', Jiazeng Chen', Yun Bai ${ }^{1}$, Zhen Li ${ }^{1}$, \\ Lirun Xiang ${ }^{1}$, Hongyue Zhai ${ }^{2}$, Qian Wang ${ }^{1}$, Jinmei Peng ${ }^{1}$, Tongqing An ${ }^{1}$, Yunchao Kan², Lunguang Yao ${ }^{2}$, \\ Xufu Yang ${ }^{4}$, Xuehui Cai ${ }^{1}$ and Guangzhi Tong ${ }^{3^{*}}$
}

\begin{abstract}
Background: Classical swine fever (CSF) is one of the most devastating and highly contagious viral diseases in the world. Since late 2014, outbreaks of a new sub-genotype 2.1d CSF virus (CSFV) had caused substantial economic losses in numbers of C-strain vaccinated swine farms in China. The objective of the present study was to explore the genomic characteristics and pathogenicity of the newly emerged CSFV isolates in China during 2014-2015.

Results: All the new 8 CSFV isolates belonged to genetic sub-genotype $2.1 \mathrm{~d}$. Some genomic variations or deletions were found in the UTRs and E2 of these new isolates. In addition, the pathogenicity of HLJ1 was less than Shimen, suggesting the HLJ1 of sub-genotype $2.1 \mathrm{~d}$ may be a moderated pathogenic isolate and the C-strain vaccine can supply complete protection.

Conclusions: The new CSFV isolates with unique genomic characteristics and moderate pathogenicity can be epidemic in many large-scale C-strain vaccinated swine farms. This study provides the information should be merited special attention on establishing prevention and control policies for CSF.
\end{abstract}

Keywords: Swine, Classical swine fever virus, Sub-genotype 2.1d, Molecular characteristics, Pathogenicity

\section{Background}

Classical swine fever virus (CSFV), the etiological agent of classical swine fever (CSF), is a single-strand, positive-sense RNA virus that belongs to the genus Pestivirus of the family Flaviviridae [1]. CSFV has a genome of about $12.3 \mathrm{~kb}$ comprising a single long open reading frame (ORF) coding for a polyprotein of 3, 898 amino acids flanked by two non-coding regions at the $5^{\prime}$ and $3^{\prime}$ untranslated region (UTR) [2]. The polyprotein undergoes proteolysis to produce four structural proteins $\left(C, E^{\text {rns }}\right.$, E1, and E2) and eight non-structural proteins $\left(\mathrm{N}^{\text {pro }}, \mathrm{P} 7\right.$, NS2, NS3, NS4A, NS4B, NS5A, and NS5B) [3, 4].

Based on E2 and partial NS5B genes, CSFV isolates were originally classified into two genotypes and five

\footnotetext{
* Correspondence: lenghan1223@126.com

†Hongliang Zhang, Chaoliang Leng and Zhijun Tian contributed equally to this work.

${ }^{3}$ Shanghai Veterinary Research Institute, Chinese Academy of Agricultural Sciences, No. 518, Ziyue Road, Minhang District, Shanghai 200241, China Full list of author information is available at the end of the article
}

sub-genotypes [5]. To date, CSFV have been divided into three groups with three or four subgroups $(1.1,1.2,1.3$; 2.1, 2.2, 2.3; and 3.1, 3.2, 3.3, 3.4) [6]. Sub-genotype 2.1 has been further divided into $2.1 \mathrm{a}$ and $2.1 \mathrm{~b}$ groups $[7,8]$. And Gong et al. reported that current CSFV sub-genotype 2.1 virus isolates in the world could be divided into 10 sub-genotypes $(2.1 \mathrm{a}-2.1 \mathrm{j})$ [9]. In mainland China, four sub-genotypes (1.1, 2.1, 2.2, and 2.3) of CSFV were identified, all of which contributed to CSFV outbreaks [10]. Shen et al. reported that subgroup 1.1 CSFV isolates circulated in some distinct region of south China [11]. However, sub-genotype $2.1 \mathrm{~b}$ has become predominant within the last decade [12-14]. In recent years, sub-genotype $2.1 \mathrm{c}$ and 1.4 were defined $[15,16]$. Recently, we confirmed a new sub-genotype $2.1 \mathrm{~d}$ of CSFV [17]. And then the newly emerged CSFV isolates of China in 2014-2015 were also characterized by our laboratory. In the present study, the complete genomes of 8 newly emerged CSFV isolates in China in 
2014-2015 were sequenced and analyzed. Moreover, the pathogenicity of one of these isolates, HLJ1, was evaluated.

\section{Methods}

\section{Clinical samples, virus isolation and virus strains}

More than 20 Clinical samples of lung, lymphatic, and spleen tissue were collected from pigs suspected to have CSFV infections in Shandong, Jiangsu, Hebei, Jilin and Heilongjiang provinces of China between October 2014 and August 2015.

Swine testicular (ST) cells were used for CSFV propagation and titration in RPMI Medium 1640 (Gibco, USA) supplemented with $10 \%$ heat-inactivated fetal bovine serum (FBS) (Invitrogen), $0.1 \mathrm{mg} / \mathrm{ml}$ streptomycin and $100 \mathrm{U} / \mathrm{ml}$ antibiotic penicillin. Clinical tissues (Lungs) were homogenized using TissuLyser II (Qiagen, Germany) and centrifuged $10,000 \times \mathrm{g}$ for $10 \mathrm{~min}$. The supernatant was filtered through a $0.45-\mu \mathrm{m}$ filter and transferred to ST cells monolayer. The cells were incubated at $37^{\circ} \mathrm{C}$ for $1 \mathrm{~h}$. Then prepared medium was added with $6 \mathrm{ml}$ in volume and the cells were incubated for another $72 \mathrm{~h}$. The cultures were harvested and then stored at $-80{ }^{\circ} \mathrm{C}$ as viral stocks. CSFV adaptation in ST cells was conducted for at least 15 passages, and some normally co-infected porcine pathogens, including porcine reproductive and respiratory syndrome virus (PRRSV), pseudorabies virus (PRV), porcine circovirus type 2 (PCV2) and mycoplasma were detected in the viral stocks.

The cultures of the third passage of CSFV HLJ1 in ST cells were quantified and used for challenge virus. The CSFV Shimen strain, a highly virulent strain isolated in China in 1945, were also used as a reference challenge virus in the present study.

\section{Primer design and RT-PCR}

Six pairs of primers based on the published known sequence of CSFV Zj0801 (GenBank accession no. FJ529205) were designed for PCR analysis (Table 1). The cultures were prepared for reverse transcription PCR (RT-PCR) using an RNA extraction QIAamp viral RNA Mini Kit (Qiagen, Germany). RT-PCR was conducted as previously reported [17].

\section{Genome cloning and sequencing}

Genome cloning and sequencing was conducted as previously reported [17]. Briefly, RT-PCR products were analyzed by using $1 \%$ agarose gel electrophoresis, and the target fragments were excised from gels for purification using a Gel Extraction Kit (OMEGA, USA). The purified PCR products were then cloned into a pMD18-T vector (TaKaRa Dalian, China) and sequenced by Comate Bioscience (Jilin, China).
Table 1 Primers used for the amplification of the full-length CSFV

\begin{tabular}{|c|c|c|c|}
\hline Fragment & Primer sequence $\left(5^{\prime}-3^{\prime}\right)^{\text {a }}$ & $\begin{array}{l}\text { Position in } \\
\text { genome }^{a}\end{array}$ & $\begin{array}{l}\text { Product } \\
\text { size }(b p)^{a}\end{array}$ \\
\hline CSFV-A & $\begin{array}{l}\text { GTATACGAGGTTAGTTCATTCTCGT } \\
\text { GATTACCAGAGAAAGCAACAAGAAT }\end{array}$ & $1-2047$ & 2047 \\
\hline CSFV-B & $\begin{array}{l}\text { GATAATAGGCCCCGGTAAATTTGAC } \\
\text { TTCCTTACAGGTCCCTCGCTAGAG }\end{array}$ & 2023-3313 & 1291 \\
\hline CSFV-C & $\begin{array}{l}\text { AAATGAGACGGGTTACAGGGTA } \\
\text { CATCCCGTAGATCTCTTCACCTCCA }\end{array}$ & $3124-4771$ & 1648 \\
\hline CSFV-D & $\begin{array}{l}\text { CATAGATGAAATAGCTGGCGGGACC } \\
\text { TAGTGCTCTGCCAGCCTCCACAGTG }\end{array}$ & $4564-7171$ & 2608 \\
\hline CSFV-E & $\begin{array}{l}\text { TCTGCTGATATCAGAGGAGCTG } \\
\text { GCTTACCCAGACTTAATGTTTCTAG }\end{array}$ & $6866-9668$ & 2803 \\
\hline CSFV-F & $\begin{array}{l}\text { GCCCTATGTAAGGTCGACACCGCTC } \\
\text { GGGCCGTTAGGAAATTACCTTAGTC }\end{array}$ & $9572-12,296$ & 2725 \\
\hline
\end{tabular}

${ }^{a}$ The sequence of primer sequence, position in genome and product size with respect to the CSFV Zj0801 (accession no. FJ529205) genome

\section{Phylogenetic analysis}

The 8 new CSFV isolates and 44 reference CSFV strains (Tables 2 and 3), based on the full of genome, were used for construction of phylogenetic tree (Fig. 1). The phylogenetic tree was constructed using MEGA 5.1 with the maximum likelihood method based on 1000 bootstraps [18]. Multiple sequence alignments were generated using MUSCLE and MEGA software [19].

\section{Nucleotides and amino acid analysis}

The complete genome sequences and deduced amino acid sequences of the 8 new isolates were analyzed and their homologies with other 8 representative CSFV strains were compared using the Clustal W method of Lasergene (Version 7.1) (DNASTAR Inc., Madison, WI, USA) (Table 4).

To explore the genetic variations of the 8 new isolates, the nucleotide sequences of the 5'UTR and the 3'UTR and the amino acid sequences of E2 were fully analyzed by CLC Sequence Viewer 8.0, together with another 23 CSFV isolates from China and other countries.

Table 2 Information of 8 newly emerged sub-genotype 2.1d CSFVs

\begin{tabular}{lllll}
\hline No. & Isolates & Sample & Time & Area \\
\hline 1 & SDLS1410 & Lung & 2014.10 & Shandong \\
2 & SDSG1410 & Lung & 2014.10 & Shandong \\
3 & JSZL1412 & Serum & 2014.12 & Jiangsu \\
4 & HB150309 & Lung & 2015.03 & Hebei \\
5 & JL150418 & Lung & 2015.04 & Jilin \\
6 & NK150425 & Lung & 2015.04 & Heilongjiang \\
7 & SDZC150601 & Lung & 2015.06 & Shandong \\
8 & HLJ1 & Lung & 2015.08 & Heilongjiang \\
\hline
\end{tabular}


Table 3 The reference CSFVs used in this study

\begin{tabular}{|c|c|c|c|c|c|}
\hline No. & Virus strain & Year & Origin & Genotype & Accession no. \\
\hline 1 & Alfort 187 & 2010 & Switzerland & 1.1 & X87939 \\
\hline 2 & Alfort A19 & 1997 & France & 1.1 & U90951 \\
\hline 3 & Brescia & 1998 & Switzerland & 1.1 & AF091661 \\
\hline 4 & C-ZJ-2008 & 2008 & China & 1.1 & HM175885 \\
\hline 5 & GZ-2009 & 2009 & China & 1.1 & HQ380231 \\
\hline 6 & HCLV & 1999 & China & 1.1 & AF091507 \\
\hline 7 & HVRI & 2006 & China & 1.1 & AY805221 \\
\hline 8 & $J \operatorname{l} 1(06)$ & 2006 & China & 1.1 & EU497410 \\
\hline 9 & Koslov & 2010 & Germany & 1.1 & HM237795 \\
\hline 10 & NG79-11 & 2014 & India & 1.1 & KC503764 \\
\hline 11 & Shimen & 1999 & China & 1.1 & AF092448 \\
\hline 12 & VB-131 & 2014 & India & 1.1 & KM262189 \\
\hline 13 & Bresciax 90 & 1990 & Netherlands & 1.2 & M31768 \\
\hline 14 & RUCSFPLUM & 2001 & USA & 1.2 & AY578688 \\
\hline 15 & CSF0277 & 1997 & Germany & 2.1 & JQ411566 \\
\hline 16 & $96 \mathrm{TD}$ & 2005 & China & $2.1 \mathrm{a}$ & AY554397 \\
\hline 17 & Paderborn & 2001 & Denmark & $2.1 \mathrm{a}$ & AY072924 \\
\hline 18 & SXCDK & 2009 & China & $2.1 \mathrm{a}$ & GQ923951 \\
\hline 19 & 0406-CH & 2005 & China & $2.1 \mathrm{~b}$ & AY568569 \\
\hline 20 & CSF1048 & 2009 & Germany & $2.1 \mathrm{~b}$ & HQ148063 \\
\hline 21 & GXWZ02 & 2003 & China & $2.1 \mathrm{~b}$ & AY367767 \\
\hline 22 & HEBZ & 2009 & China & $2.1 \mathrm{~b}$ & GU592790 \\
\hline 23 & HuN23-2013 & 2013 & China & $2.1 b$ & KP233071 \\
\hline 24 & SXYL2006 & 2006 & China & $2.1 \mathrm{~b}$ & GQ122383 \\
\hline 25 & YC11WB & 2011 & Korea & $2.1 \mathrm{~b}$ & KC149990 \\
\hline 26 & GXF29/2013 & 2013 & China & $2.1 \mathrm{c}$ & KP233070 \\
\hline 27 & HNLY-2011 & 2011 & China & $2.1 \mathrm{c}$ & JX262391 \\
\hline 28 & HNSD-2012 & 2012 & China & $2.1 \mathrm{c}$ & JX218094 \\
\hline 29 & Heb52010 & 2010 & China & $2.1 d$ & JQ268754 \\
\hline 30 & HLJZZ2014 & 2014 & China & $2.1 d$ & KU375260 \\
\hline 31 & PC11WB & 2011 & Korea & $2.1 d$ & KC149991 \\
\hline 32 & Zj0801 & 2008 & China & $2.1 d$ & FJ529205 \\
\hline 33 & 39 & 2001 & China & 2.2 & AF407339 \\
\hline 34 & LAL-290 & 2012 & India & 2.2 & KC851953 \\
\hline 35 & Alfort/Tuebingen & 1989 & Germany & 2.3 & $J 04358$ \\
\hline 36 & Borken & 2006 & Germany & 2.3 & GU233731 \\
\hline 37 & Euskirchen & 2005 & Germany & 2.3 & GU233732 \\
\hline 38 & Hennef & 2009 & Germany & 2.3 & GU233733 \\
\hline 39 & Jambul & 2007 & Bulgaria & 2.3 & HQ148062 \\
\hline 40 & Novska & 2002 & Croatia & 2.3 & HQ148061 \\
\hline 41 & Roesrath & 2009 & Germany & 2.3 & GU233734 \\
\hline 42 & Sp01 & 2001 & Spain & 2.3 & FJ265020 \\
\hline
\end{tabular}

Table 3 The reference CSFVs used in this study (Continued)

\begin{tabular}{llllll}
\hline No. & Virus strain & Year & Origin & Genotype & Accession no. \\
\hline 43 & Uelzen & 2004 & Germany & 2.3 & GU324242 \\
44 & Jj9811 & 1998 & Korea & 3.2 & KF669877 \\
45 & P97 & 2006 & - & 3.4 & L49347 \\
46 & TWN & 1994 & China & 3.4 & AY646427 \\
\hline
\end{tabular}

\section{Experimental CSFV inoculation of SPF piglets}

A total of 10 five-week-old specific pathogen-free (SPF) Bama piglets were obtained from the Experimental Animal Center of the Harbin Veterinary Research Institute, and were randomly divided into three groups (A, B, and C) and maintained in individual biosafety rooms. The piglets in group $\mathrm{A}(n=3)$ were inoculated intramuscularly $(2 \mathrm{ml})$ with Shimen strain at a dose of $1 \times 10^{7.0}$ copies. The piglets in group B $(n=3)$ were inoculated with the new CSFV HLJ1 strain with the same method and dose as group A. The piglets in group $C(n=4)$ were mock infected with $2 \mathrm{ml}$ RPMI Medium 1640. Clinical symptoms were observed daily throughout the study, and rectal temperatures were recorded daily before feeding. Blood samples were collected at $0,7,14,21,28,31$, and 35 days post inoculation (DPI). All remaining pigs were euthanized on 35 DPI. Tissue samples were obtained from the hearts, livers, spleens, lungs, kidney, lymph nodes, tonsils, small intestines, bladders, and stomach for virus detection by RT-PCR, and histopathological or immunohistochemistry (IHC) examination. To determine the level of virulence of the new CSFV HLJ1 strain, the clinical scoring (CS) system was used as described previously [20].

\section{Histopathological examination and IHC}

Tissue samples were subjected to histopathological and IHC examination as previously described [21, 22]. Briefly, tissue samples were fixed in $10 \%$ neural buffered formalin for $48 \mathrm{~h}$, embedded in paraffin wax and sectioned. Thin sections with $4-\mu \mathrm{m}$ thickness stained with hematoxylin and eosin ( $\mathrm{H}-\mathrm{E}$ staining) for histopathological examinations. 4- $\mu \mathrm{m}$ sections were treated with $3 \%$ hydrogen peroxide in PBS for $20 \mathrm{~min}$ followed by washes in PBS and digestion with $0.05 \%$ protease (protease XIV; Sigma) for $5 \mathrm{~min}$ at $37{ }^{\circ} \mathrm{C}$. Then washes with PBS, sections were incubated in blocking solutions with $8 \%$ skim milk for $40 \mathrm{~min}$ at room temperature. After washes with PBS, sections were incubated for $2 \mathrm{~h}$ at $4{ }^{\circ} \mathrm{C}$ with rabbit antiserum against CSFV (saved by our laboratory) diluted 1:200 in PBS. Then washes with PBS, sections were incubated with anti-rabbit IgG-peroxidase antibody produced in goat (Sigma) diluted 1:400 in PBS for $40 \mathrm{~min}$ at room temperature. 


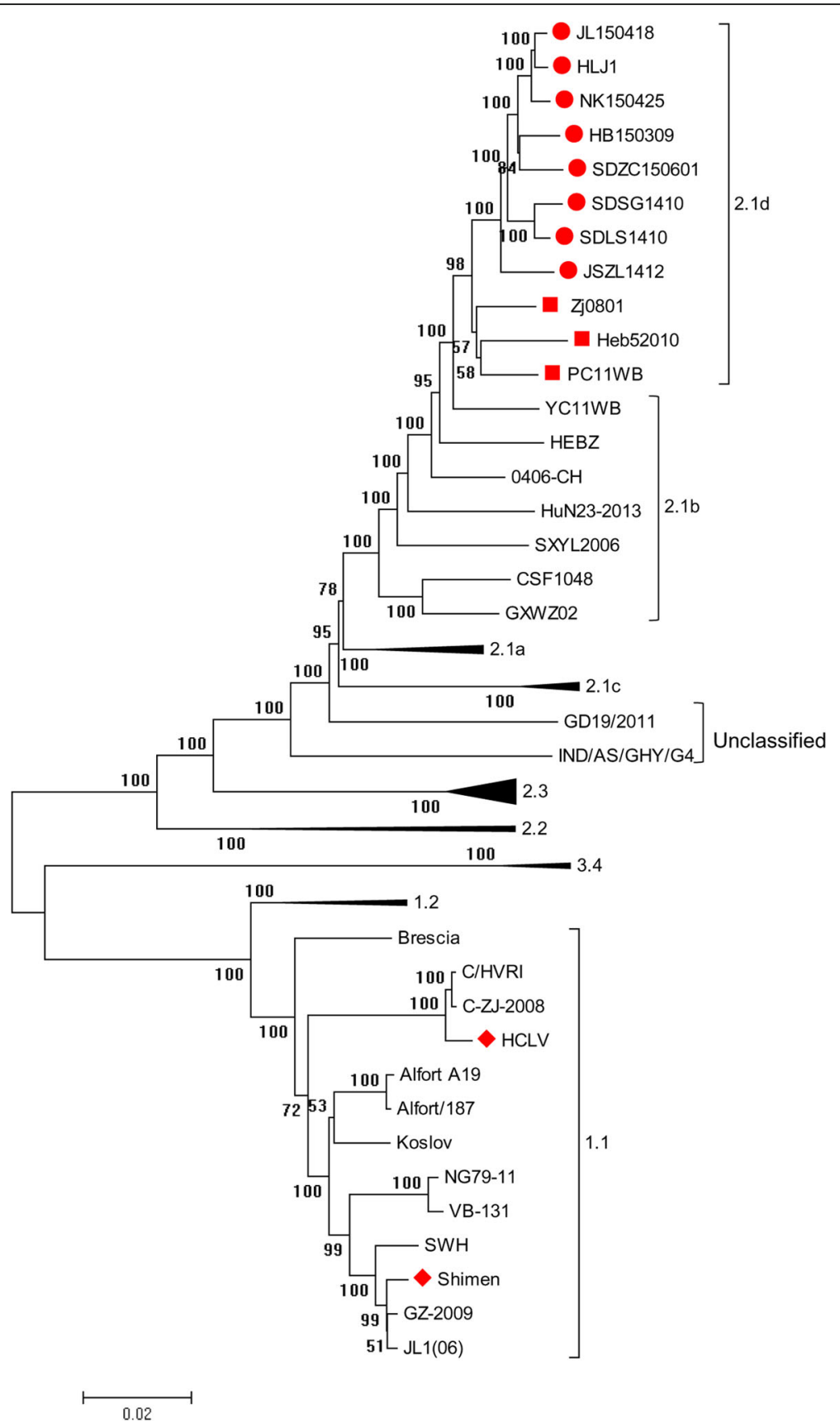

Fig. 1 Phylogenetic analysis of the 8 new isolates and 44 reference strains based on the complete CSFV genomes. The 8 new CSFV isolates and 3 reference strains were located in a branch belonging to $2.1 \mathrm{~d}$ sub-genotype, labeled by and respectively. The Shimen strain and its attenuated live vaccine strain, HCLV, were located in another branch belonging to 1.1 sub-genotype, labeled by

\section{Results}

Virus isolation and genome sequencing

8 new CSFV isolates named HLJ1, SDSG1410,

SDLS1410, JSZL1412, HB150309, JL150418,

NK150425 and SDZC150601, from 5 provinces

(Shandong, Jiangsu, Hebei, Jilin and Heilongjiang) in

China, were acquired and sequenced (Table 2). And

their complete genome sequences were 12,295,
$12,295,12,296,12,297,12,295,12,295,12,295$ and 12,294 nucleotides in length, respectively.

\section{Phylogenetic analysis}

A total of 8 new CSFV isolates and 44 reference strains, based on the full genome, were used to construct phylogenetic tree (Fig. 1). CSFV isolates were divided into genotype 1, 2 and 3. Genotype 2 isolates were further 
Table 4 Detailed comparison of the full-length genomes of the 8 newly emerged sub-genotype 2.1d CSFVs to other CSFV representative isolates (\%)

\begin{tabular}{|c|c|c|c|c|c|c|c|c|}
\hline & Shimen (1.1) & Paderborn (2.1a) & HEBZ (2.1b) & HNSD-2012 (2.1c) & Zj0801 (2.1d) & CSFV39 (2.2) & Alfort (2.3) & TWN (3.4) \\
\hline \multicolumn{9}{|l|}{ Nucleotides } \\
\hline $5^{\prime} \cup T R$ & $91.4-92.2$ & $96.5-97.3$ & $95.4-96.2$ & $94.4-95.2$ & $97.0-98.7$ & $91.6-92.5$ & $93.3-94.1$ & $90.3-91.9$ \\
\hline$N^{\text {pro }}$ & $87.1-88.1$ & $94.0-94.8$ & $94.2-95.4$ & $92.1-92.7$ & $96.8-98.0$ & $88.3-89.1$ & $88.3-88.9$ & $84.1-85.3$ \\
\hline C & $84.5-86.2$ & $94.3-95.3$ & $93.3-94.6$ & $90.2-92.3$ & $95.6-97.3$ & $89.6-90.9$ & 89.9-91.2 & $83.2-84.8$ \\
\hline$E^{\mathrm{rns}}$ & $84.1-85.3$ & $93.2-94.6$ & $96.5-97.1$ & $92.1-93.1$ & $97.7-98.2$ & $89.4-89.7$ & $89.6-90.5$ & $82.4-8.4$ \\
\hline E1 & $84.4-85.3$ & $93.8-94.7$ & $96.4-97.3$ & $91.3-92.1$ & $97.6-98.5$ & $90.3-91.5$ & 88.4-89.6 & $81.4-82.1$ \\
\hline E2 & $83.5-84.3$ & $93.5-94.3$ & $95.5-96.5$ & $90.1-91.0$ & $96.6-97.1$ & $87.0-87.5$ & $86.9-87.8$ & $82.0-82.4$ \\
\hline P7 & $79.7-81.6$ & $90.8-93.2$ & $95.2-97.1$ & $91.8-94.2$ & $95.7-98.6$ & $87.4-89.4$ & 88.4-90.3 & $82.6-85.5$ \\
\hline NS2 & $82.6-83.4$ & $92.9-93.4$ & $96.2-96.6$ & $91.8-92.3$ & $96.9-97.5$ & $89.1-89.6$ & $88.5-89.1$ & $80.2-81.0$ \\
\hline NS3 & $86.4-87.0$ & $94.6-95.1$ & $95.7-96.1$ & $92.8-93.6$ & $97.1-97.4$ & $90.3-91.0$ & $90.8-91.7$ & $85.4-86.1$ \\
\hline NS4A & $86.2-87.8$ & $94.7-96.3$ & $94.2-95.8$ & $91.0-92.6$ & $97.9-98.9$ & $87.8-89.4$ & $87.8-89.4$ & $82.5-94.1$ \\
\hline NS4B & $85.8-86.5$ & $92.8-93.6$ & $95.0-95.8$ & $90.1-91.1$ & $96.6-97.8$ & $89.3-90.0$ & $88.4-89.1$ & $83.1-84.1$ \\
\hline NS5A & $83.7-84.3$ & $93.6-94.0$ & $96.2-96.7$ & $90.7-91.3$ & $97.0-97.3$ & $83.8-84.3$ & $90.6-90.9$ & $82.5-82.9$ \\
\hline NS5B & $84.7-85.3$ & $94.9-95.3$ & $95.8-96.4$ & $92.5-93.2$ & $97.5-97.8$ & $85.2-85.7$ & $89.5-89.9$ & $83.4-83.7$ \\
\hline 3'UTR & $84.1-85.0$ & $93.8-95.1$ & $94.7-96.0$ & $93.8-95.6$ & $97.3-98.7$ & $83.6-84.4$ & $92.9-94.2$ & $82.6-84.0$ \\
\hline Complete & $85.0-85.3$ & $94.1-94.4$ & $95.9-96.2$ & $91.9-92.3$ & $97.2-97.5$ & 87.9-88.2 & $89.6-89.9$ & $83.4-83.7$ \\
\hline \multicolumn{9}{|l|}{ Amino acid } \\
\hline $\mathrm{N}^{\text {pro }}$ & $91.7-92.9$ & $94.6-95.8$ & $95.8-97.0$ & $94.6-95.8$ & $96.4-97.6$ & $91.7-92.9$ & $92.3-92.9$ & $90.5-91.7$ \\
\hline C & $92.9-94.9$ & $93.9-97.0$ & $94.9-97.0$ & $91.9-94.9$ & $96.0-98.0$ & $91.9-96.0$ & 92.9-94.9 & $88.9-90.9$ \\
\hline$E^{\text {rns }}$ & $89.0-89.9$ & $96.9-97.8$ & $97.4-98.2$ & $96.9-97.8$ & $98.7-99.6$ & $94.3-95.2$ & $95.6-96.0$ & $90.3-91.2$ \\
\hline E1 & $92.8-93.8$ & $97.4-98.5$ & 96.9-97.9 & $94.9-95.9$ & $99.5-100.0$ & $96.9-97.9$ & $96.4-97.4$ & $88.7-90.3$ \\
\hline E2 & $90.1-91.2$ & $95.4-96.5$ & $96.2-97.6$ & $94.9-95.7$ & $97.1-98.1$ & $90.9-92.0$ & $91.4-92.5$ & $89.0-90.1$ \\
\hline P7 & 88.4-89.9 & $95.7-98.6$ & $92.8-95.7$ & $94.2-97.1$ & $95.7-98.6$ & $94.2-95.7$ & $94.2-95.7$ & $91.3-94.2$ \\
\hline NS2 & $89.7-90.6$ & $95.6-96.3$ & $97.4-98.0$ & $95.8-96.3$ & $97.2-98.0$ & $94.7-95.2$ & $93.4-94.1$ & $86.9-87.7$ \\
\hline NS3 & $97.7-98.5$ & $98.7-99.6$ & $98.4-99.1$ & $98.1-98.8$ & $98.1-98.8$ & 97.9-98.7 & $98.4-99.1$ & $97.8-98.7$ \\
\hline$N S 4 A^{a}$ & 98.4 & 100.0 & 98.4 & 95.2 & 100.0 & 96.8 & 100.0 & 95.2 \\
\hline NS4B & $95.1-96.3$ & $97.4-98.6$ & $97.7-98.6$ & $98.3-99.4$ & $98.3-98.8$ & $96.5-97.1$ & $97.4-98.6$ & $93.7-94.8$ \\
\hline NS5A & $87.5-89.0$ & $95.6-96.6$ & $96.2-97.4$ & $93.2-94.8$ & $96.4-97.2$ & $87.1-88.0$ & $93.2-94.0$ & $86.3-87.3$ \\
\hline NS5B & $92.3-93.2$ & $97.5-98.2$ & $97.6-98.3$ & $97.3-98.0$ & $98.0-98.7$ & $93.0-93.9$ & $96.2-97.2$ & 89.8-90.9 \\
\hline
\end{tabular}

${ }^{\text {a }}$ The amino acid homology of NS4A protein of the 8 new isolates between each other was $100 \%$

divided into sub-genotype 2.1, 2.2, and 2.3, and sub-genotype 2.1 isolates could be further subdivided into $2.1 \mathrm{a}, 2.1 \mathrm{~b}, 2.1 \mathrm{c}$, and $2.1 \mathrm{~d}$, which were consistent with the classification results based on E2 and partial NS5B gene [17]. Phylogenetic tree also showed that the 8 new isolates and 3 reference CSFVs (Zj0801, Heb52010 and PC11W) belong to sub-genotype 2.1d. The virulent Shimen strain and its attenuated live vaccine strain HCLV belong to sub-genotype 1.1.

\section{Analysis of full-length genomic sequences}

The complete nucleotide sequences of the 8 new CSFV isolates were compared with 8 representative CSFV isolates, including Shimen, Paderborn, HEBZ, HNSD-20, Zj0801, CSFV39, Alfort and TWN (Table 4). Results indicated that the 8 new isolates shared 97.2-97.5\% homology with $2.1 \mathrm{~d}$ isolate $\mathrm{Zj0801}$, the most closely related strain. Other representative CSFV strains similar to the new isolates were included 2.1a isolate Paderborn and 2.1c isolate HNSD-2012, which shared 94.1-94.4\% and $91.9-92.3 \%$ homology, respectively. In addition, they shared only $83.4-89.9 \%$ homology with 1.1 isolate Shimen, 2.2 isolate CSFV39, 2.3 isolate Alfort or 3.4 isolate TWN. Taken together, these results indicate that all these isolates belong to sub-genotype $2.1 \mathrm{~d}$, which was consistent with the result of phylogenetic analysis.

To further examine the genomic variation of the 8 isolates, their genomic characteristics were analyzed in detail. Compared with the representative isolates, the 5'UTRs of the new isolates were the most conserved 
regions in the genomes, which exhibited 94.4-98.7\% homology with 2.1 isolates Paderborn, HEBZ, HNSD-2012 or Zj0801, 93.3-94.1\% homology with 2.3 isolate Alfort, 91.6-92.5\% homology with 2.2 isolate CSFV39 and 90.3-92.2\% homology with 1.1 isolate Shimen or 3.4 isolate TWN. In addition, the amino acid identities of NS3, NS4A and NS4B between the new isolates and representative isolates were higher than other regions of the CSFV genome, and the homologies were $97.7-99.6 \%, 95.2-100 \%$ and $93.7-99.4 \%$, respectively. The detailed identities of the three isolates and eight other representative strain isolates are summarized in Table 4.

\section{Sequence analysis of UTRs}

Compared with sub-genotype 1.1 isolates, the 5'UTRs of the new isolates had a nucleotide A deletion at position $49\left(\mathrm{~A}^{49}\right)$, which was similar to most of the 2.1 isolates (Fig. 2). In addition, the 5'UTRs of the 6 new isolates (SDSG1410, HB150309, JL150418, NK150425, SDZC150601 and HLJ1) had two continuous nucleotide A deletions at positions 357-358 compared with 2.3 isolate Broken (GU233731), while other 2 new isolates (SDLS1410 and JSZL1412) show only one nucleotide A deletion at these positions (Fig. 2). And most of the CSFV isolates shared the characteristic of the two continuous deletions at these positions (Fig. 2).

Compared with the vaccine strain HCLV, the 3'UTRs of all the 8 new isolates had 12 continuous nucleotide deletions (TTTTTCTTTTTT) at positions 63-74, which were similar to most of the CSFV isolates (Fig. 2). However, among the 23 reference CSFV isolates, the CSFV-PK15C-5NG79-11 (KC503764) strain had $7 \mathrm{nu}-$ cleotide deletions (CTTTTTT), and the CSFV/IVRI/ VB-131 (KM262189) strain had 9 nucleotide deletions (TTCTTTTTT). The other two strains, RUCSFPLUM (AY578688) and Rovac (KJ873238), had 11 nucleotide deletions (TTTTTCTTTTTT) at these positions (Fig. 2). In addition, compared with 1.1 isolates, the 3'UTRs of most 2.1 isolates, including the 8 new isolates, had two discontinuous nucleotide $\mathrm{T}$ deletions at positions 182 and 210, respectively (Fig. 2).

\section{Amino acid analysis of E2}

The E2 amino acid sequences of the 8 new isolates and 23 reference isolates were compared and analyzed (Fig. 3). And some unique molecular characteristics were found for the new isolates, including the amino acid $\mathrm{R}$ at

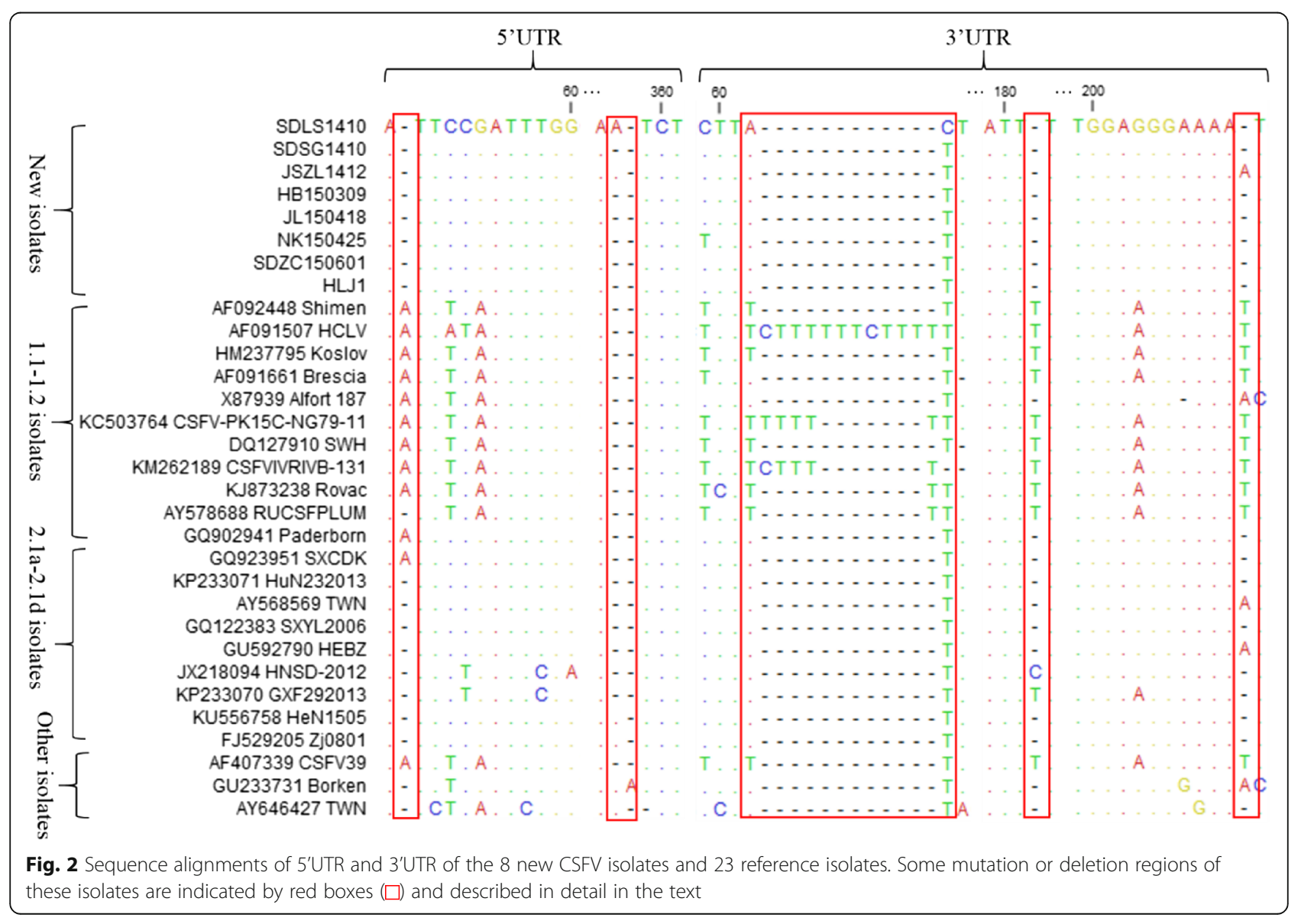




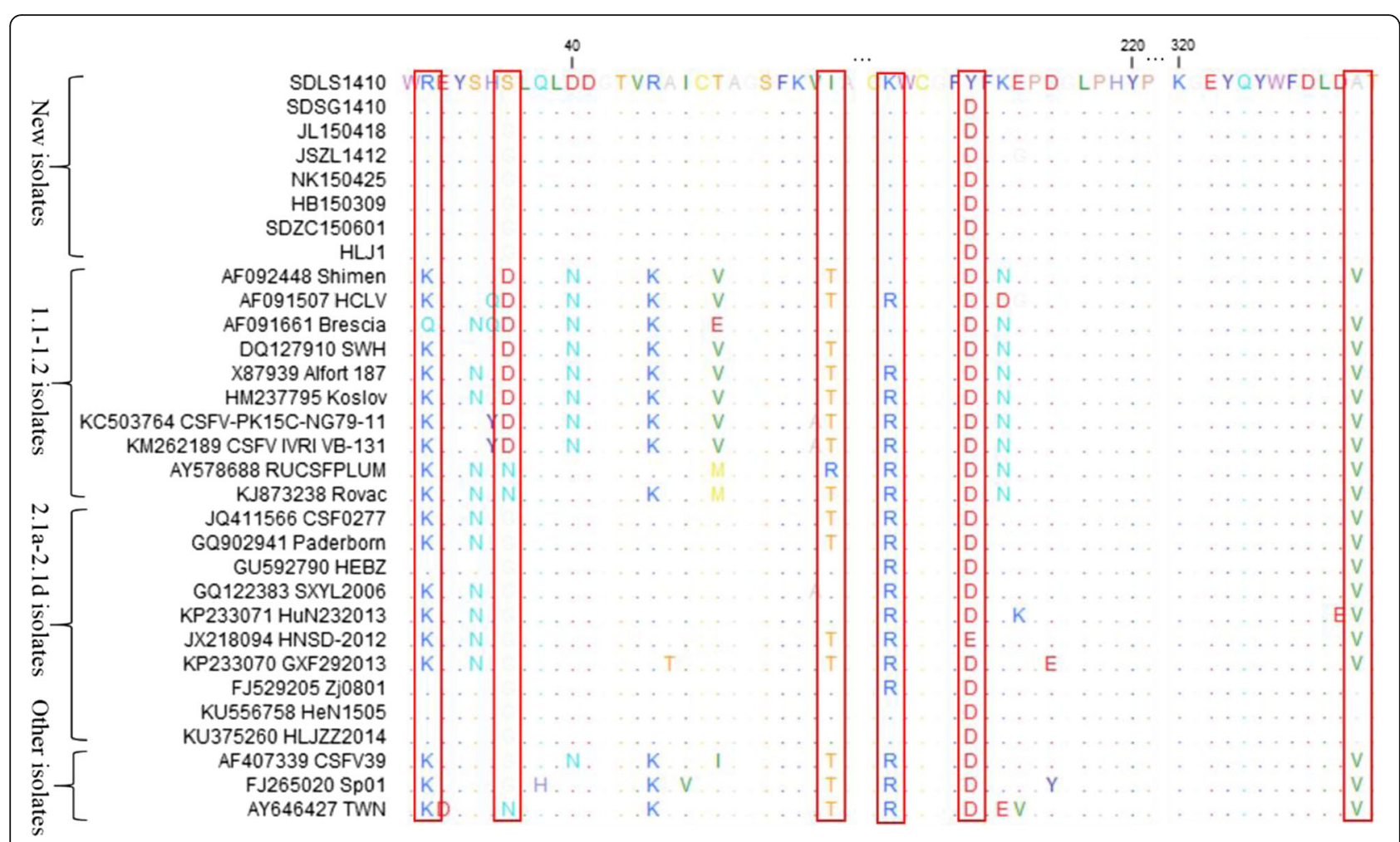

Fig. 3 Amino acid sequence alignments of E2 genes of the 8 new CSFV isolates and 23 reference isolates. The special mutation positions of these isolates are indicated by red boxes $(\square)$ and described in detail in the text

position $31\left(\mathrm{R}^{31}\right), \mathrm{I}^{56}, \mathrm{~K}^{205}$ and $\mathrm{A}^{331}$. And these molecular characteristics were consistent with $2.1 \mathrm{~d}$ isolates and some $2.1 \mathrm{~b}$ isolates. In addition, the two new isolates, SDLS1410 and SDSG1410, were $\mathrm{S}^{36}$, different from all other isolates. Similarly, at position 210, the SDLS1410 was amino acid Y, and all other sub-genotype isolates were amino acid D (Fig. 3).

\section{Experimental CSFV inoculation of SPF piglets}

The piglets in groups A and B displayed obvious clinical signs, including fever, anorexia and diarrhea, reddening of the conjunctiva and ocular discharge, shivering, and lethargy. In addition, the onset of fever was significantly sooner in group A (Shimen inoculation) than in group B (HLJ1 inoculation) (Fig. 4a). Furthermore, 3/3 piglets in group $\mathrm{A}$ died and $2 / 3$ piglets in group $\mathrm{B}$ died at $11 \mathrm{DPI}$ (Fig. 4b). The piglets in group $\mathrm{C}$ showed no clinical signs throughout the experiment. Based on the CS system, each pig was judged daily after experimental inoculation. The peak CS value of Shimen-infected and HLJ1-infected pigs were determined to be 25-26 and $12-14$, respectively, indicating that the HLJ1 strain was moderately virulent ( $5<$ peak CS $\leq 15)$ (Fig. 4c). The groups A and B piglets showed lesions typical of CSF, such as necrosis in the tonsils, hemorrhaging in the lymph nodes, splenic infarcts and pint hemorrhaging in almost all of the organs (Fig. 5a1-a3 and b1-b3). Histopathology revealed lymphocyte decrease accompanied by partial lymphoid follicle atrophy in tonsils, interstitial pneumonia, and inflammatory lymphohistiocytic infiltrates in the kidney and liver, necrosis of white pulp and lymphocyte depletion in the spleen and varied degrees of hyperemia and hemorrhage in most tissues (Fig. 5a4-a6 and b4-b6 ). In addition, the immunoreactivity was observed in the crypt of tonsil of the piglets in groups $\mathrm{A}$ and B (Fig. 5a7 and b7). Virus detection of different tissues and serum samples showed that all samples of piglets in groups A and B were positive, while samples of piglets in group $\mathrm{C}$ were negative (data not shown).

\section{Discussion}

CSF is one of the most devastating and highly contagious viral diseases that has caused huge economic losses to pig farms and remains a lingering problem in many parts of the world [23]. Since nationwide vaccinations were implemented, large CSF outbreaks have been rare. However, no regions have been declared free of CSF, and there is still a long way to go to control and ultimately eradicate CSF in China [24]. Four CSFV sub-genotypes, 1.1, 2.1, 2.2, and 2.3, have been identified in mainland China [10]. And a new sub-genotype 2.1c was emerged in China recently [15]. Since late 2014, a 

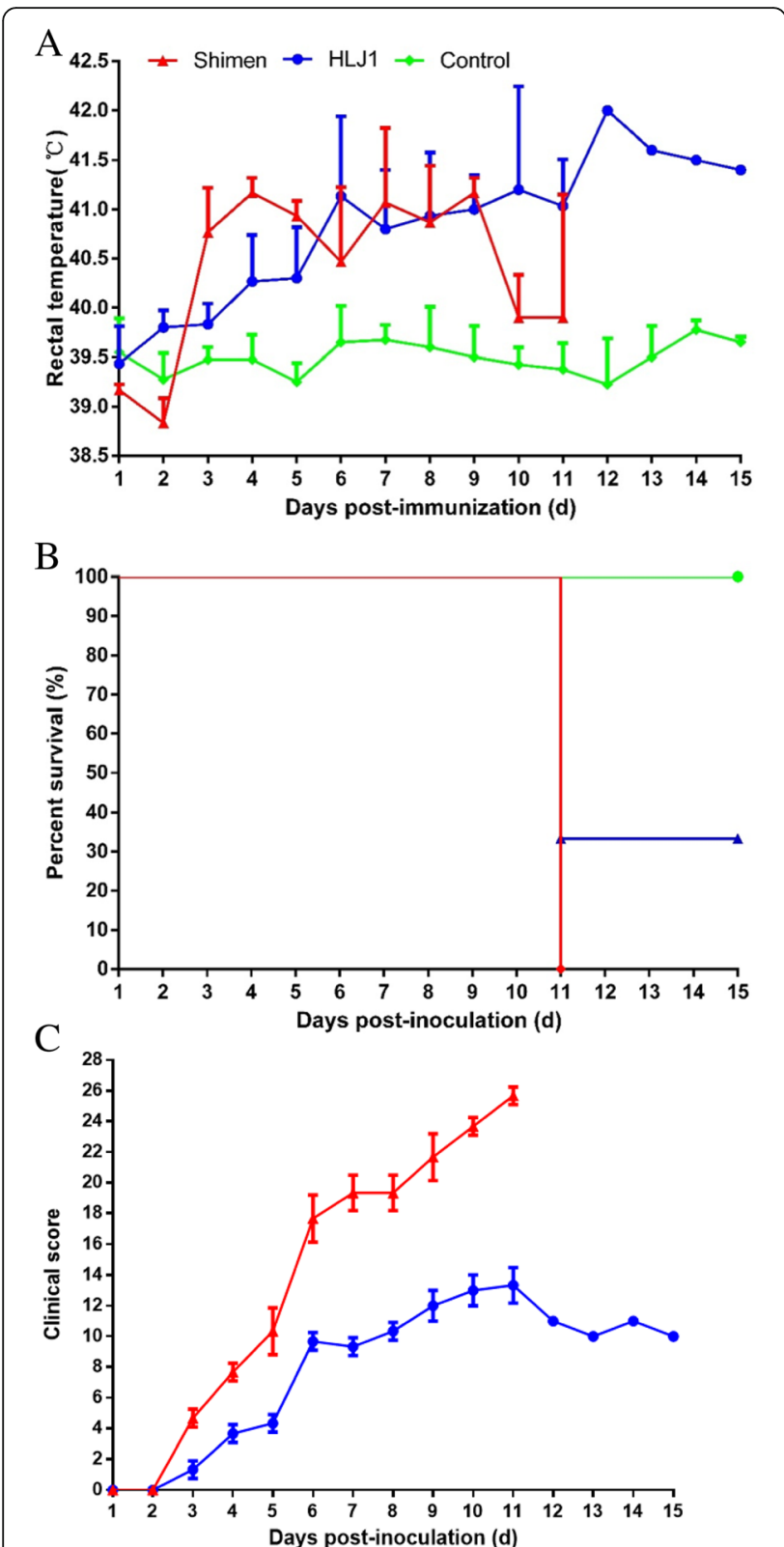

Fig. 4 Rectal temperatures (a), mortality rates (b) and clinical scores (c) of piglets inoculated with CSFV Shimen and HU1. Mean temperatures \pm standard deviations (error bars) are shown (group $\mathbf{a}, n=3$; group $\mathbf{b}$, $n=3$ and group $\mathbf{c}, n=4)$. Rectal temperatures $>40.5{ }^{\circ} \mathrm{C}$ were defined as fever

new sub-genotype 2.1d isolates were emerged and identified in China $[17,25]$. In the present study, we first reported 8 newly emerged CSFV isolates in China in 2014-2015.

The 5'UTR, partial E2 (190 nt), and partial NS5B (409 nt) gene sequences have been widely used for classification of CSFV isolates [26, 27]. Postel et al. reported that the full-length E2 gene sequence provides better resolution for phylogenetic analysis [28]. And identification of sub-genotypes $2.1 \mathrm{c}$ and $2.1 \mathrm{~d}$ was based on the full-length E2 gene sequence [15, 17]. Some labs reported that the whole genome sequence of CSFV could provide more reliable classification criterion [29, 30]. In the present study, the phylogenetic tree was constructed based on the complete genomes. And 8 new isolates were classified into $2.1 \mathrm{~d}$ sub-genotype (Fig. 1), which was consistent with the results that the phylogenetic tree was constructed based on the full-length E2 gene or partial NS5B gene (data not shown). Interestingly, the $2.1 \mathrm{~d}$ isolates were located in a relatively concentrated branch close to $2.1 \mathrm{~b}$ isolates (Fig. 1). The reason may be that sub-genotype $2.1 \mathrm{~b}$ isolates have become predominant within the last decade in China and the new $2.1 \mathrm{~d}$ isolates are found to possibly diverge from $2.1 \mathrm{~b}$ isolates [12-14, 31].

The complete genomic sequences of the 8 new CSFV isolates were compared with other representative CSFV isolates (Table 4). The results indicated that the 8 isolates shared the highest nucleotide homology with Zj0801, the representative strain of sub-genotype 2.1d. And these new isolates also showed high homology with the sub-genotype $2.1 \mathrm{~b}$ isolate, HEBZ. These results were consistent with the result of phylogenetic analysis. In addition, we also found that the 5'UTRs of the 8 isolates were the most conserved regions in the genomes. And NS3, NS4A and NS4B proteins were more conserved than other regions in the CSFV genome.

The 5'UTR and 3'UTR have been documented to be crucial regulatory elements in the CSFV genome [32]. Sequence alignment showed that the 5'UTRs of the 8 new isolates had the same nucleotide deletions at positions 44 compared with 1.1 isolates (Fig. 2). However, compared with 2.3 isolate Broken, the 6 new isolates (SDSG1410, HB150309, JL150418, NK150425, SDZC150601 and HLJ1) had two continuous nucleotide A deletions at positions 357-358, which was identical to most of the reference CSFV isolates. And other 2 new isolates (SDLS1410 and JSZL1412) show only one nucleotide A deletion at these positions (Fig. 2). Whether the deletions affect the structural characteristics of the 5'UTRs requires experimental confirmation. However, CSFV virulence may vary according to the number and shape of the pseudoknot loop in the secondary structure of 5'UTR and its positional direction in three-dimensional space $[29,33]$. Thus, the two groups isolates may have different virulence characteristics.

The 3'UTR is the region with the most variation in the CSFV genome. And the poly-T deletion in the 3'UTR is an important virulence factor and becomes an attenuated-symptom phenotype of CSFV [34]. In the present study, we found that all the 8 new isolates had the poly- $\mathrm{T}$ deletion region compared to the vaccine strain HCLV (Fig. 2). We conclude that these isolates 


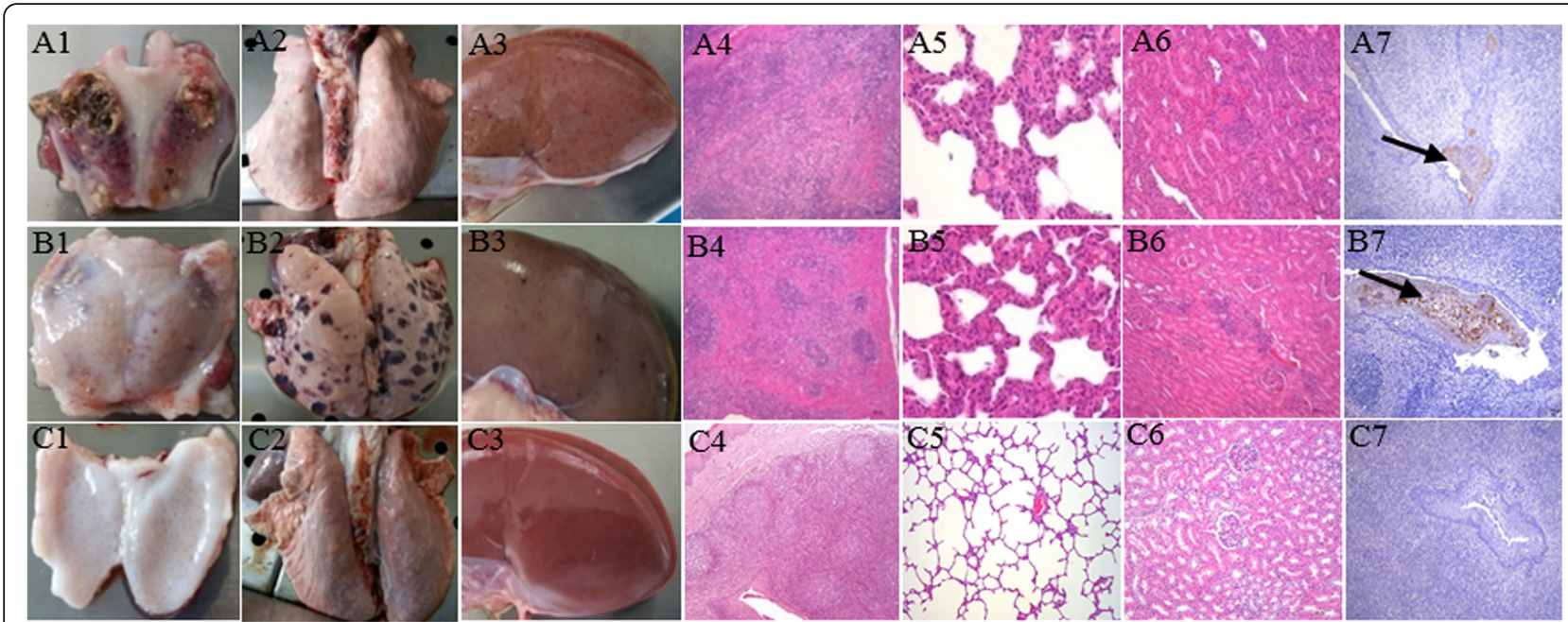

Fig. 5 Gross and histological lesions of tonsils, lungs and kidneys of piglets in different groups. Piglets infected with Shimen (a1-a3) or HLJ1 (b1-b3) showed obvious necrosis, hemorrhaging or hemorrhagic spots than mock-infected (c1-c3) piglets. Histopathology of tonsils, lungs and kidneys of Shimen- (a4-a6), HLJ1-infected (b4-b6) piglets manifested partial lymphoid follicle atrophy, interstitial pneumonia or lymph histiocytic infiltrates than control (c4-c6). Viral antigen of CSFV was detected in the tonsils of piglets in Shimen- or HLJ1-infected groups by means of IHC staining $(\mathbf{a} 7, \mathbf{b} 7)$. The tonsils of piglets in control group were negative for CSFV (C7). Original magnification, $\times 200$

were virulent wild CSFV strains with similar virulence. In addition, we also found several previous reported isolates, including CSFV-PK15C-NG79-11, CSFV/IVRI/ VB-131, RUCSFPLUM and Rovac, with different deletions in this region, which suggested the differences in the pathogenicity of these strains. Recently, a unique poly-T tract was discovered in the 3'UTR of the CSFV Pinar del Rio strain compared with all other CSFV isolates [35]. And whether this novel insertion affect the pathogenicity of the virus remains unknown. In addition, many studies reported that NS3, NS5A and NS5B of CSFV can interact with 3'UTR to regulate viral RNA synthesis and replication [36-38]. In this study, we also found the 3'UTRs of the 8 new isolates and most sub-genotype 2.1 isolates had two discontinuous nucleotide deletions compared with those of 1.1 isolates (Fig. 2). Whether nucleotide deletions in the 3'UTR affect the interactions with other proteins requires further research.

The E2 protein is the most antigenic protein of CSFV and is involved in virus neutralization [39]. Four antigenic domains, A (86-176 amino acids), B (1-83 amino acids), C (1-110 amino acids), and D (86-110 amino acids), have been mapped on E2 [40]. And domain A has been subdivided into A1, A2, and A3 [40]. In the present study, we found several unique amino acid substitutions for the new isolates on these domains and other regions (Fig. 3). However, the influence of these substitutions on the structure and function of E2 requires further study. In addition, the six cysteines at positions 4, 48, 103, 129, 139 , and 167, which were essential for binding by monoclonal antibodies of the four domains, showed no variation in the E2 proteins of these isolates [40].
Furthermore, the potential N-glycosylation sites in the E2 proteins of the 8 isolates were consistent with previous isolates.

The CSFV genotype 1 isolates, such as shimen, showed high pathogenicity, and the Chinese lapinized attenuated vaccine (C-strain) was acquired through the attenuation of the strain, while the genotype 2 or 3 isolates revealed moderate or low virulence [41, 42]. However, Floegel-Niesmann et al. reported that two CSFV isolates, CSF0277 and CSF0849, belonged to sub-genotype 2.1, had been characterized as moderately and highly virulent strains, respectively [43]. In the present study, the pathogenicity of the new HLJ1 isolate which belonged to sub-genotype $2.1 \mathrm{~d}$ was assessed. Results of animal experiments indicated that the pathogenicity of HLJ1 was less than Shimen (Figs. 4 and Fig. 5), and was similar to HLJZZ2014, a sub-genotype $2.1 \mathrm{~d}$ isolate with moderate virulence identified recently [44]. In recent years, the C-strain vaccine was widely used to prevent CSFV infection in China. And this vaccine can supply complete protection against the HLJ1 challenging in the lab (data not shown). However, the new sub-genotype $2.1 \mathrm{~d}$ CSFV isolates could also be epidemic in many immunized pig farms, which was worth of vigilant. The deeper reasons, such as immunization program, vaccine quality, interference by other pathogens and so on, need further study.

\section{Conclusion}

The complete genomes of 8 new CSFV isolates were fully analyzed in the present study. We found that the 8 isolates all belonged to genetic subgroup $2.1 \mathrm{~d}$. And some genomic variations or deletions were found in the UTRs 
and E2. Furthermore, we found that the pathogenicity of the new HLJ1 isolate was less than Shimen. And the sub-genotype $2.1 \mathrm{~d}$ isolates could be classified into the CSFV strains with moderate virulence. In any case, the epidemic of these isolates should be focus on monitoring and the information of the present study should be considered when establishing control and vaccine strategies for CSF.

\section{Abbreviations}

CSF: Classical swine fever; CSFV: Classical swine fever virus; DPI: Days post inoculation; FBS: Fetal bovine serum; ORF: Open reading frame; SPF: Specific pathogen-free; ST: Swine testicular; UTR: Untranslated region

\section{Acknowledgements}

We thank Fei Xiao, Shouping Hu and Xijun He (Pathology laboratory, Harbin Veterinary Research Institute, CAAS) for doing the IHC.

\section{Funding}

The National Key R\&D Program (2016YFD0500100) and the National Natural Science Foundation of China (31502097), the Scientific and Technological Project of Henan Province (182102110240) and the Foundation of Nanyang Normal University (15082) supported this study.

\section{Availability of data and materials}

All data generated or analyzed during this study are included in this published article.

\section{Authors' contributions}

HLZ, CLL, XFY, XHC, ZJT and GZT conceived and designed the experiment. $H L Z, C X L, J Z C, Y B, Z L, L R X$ and HYZ performed the experiment. HLZ, CLL, QW, JMP, TQA, YCK and LGY performed analysis and prepared the manuscript. All authors read and approved the final manuscript.

\section{Ethics approval and consent to participate}

Experimental animals used in the study were cared for in accordance with the internationally accepted standards for the care and handling of laboratory animals. This study was granted approval by the Animal Ethics Committee of School of Harbin Veterinary Research Institute of the Chinese Academy of Agricultural Sciences. The Animal Ethics Committee approval number was SYXK (Hei) 2,011,022

\section{Competing interests}

The authors declare that they have no competing interests.

\section{Publisher's Note}

Springer Nature remains neutral with regard to jurisdictional claims in published maps and institutional affiliations.

\section{Author details}

${ }^{1}$ State Key Laboratory of Veterinary Biotechnology, Harbin Veterinary Research Institute, Chinese Academy of Agricultural Sciences, Harbin 150001, China. ${ }^{2}$ Henan Key Laboratory of Insect Biology in Funiu Mountain, Henan Provincial Engineering Laboratory of Insects Bio-reactor, China-UK-NYNU-RRes Joint Laboratory of Insect Biology, Nanyang Normal University, Nanyang 473061, China. ${ }^{3}$ Shanghai Veterinary Research Institute, Chinese Academy of Agricultural Sciences, No. 518, Ziyue Road, Minhang District, Shanghai 200241, China. ${ }^{4}$ North Guangdong Collaborative Innovation and Development Center of Pig Farming and Disease Control, Shaoguan University, Shaoguan 512005, China.

Received: 18 September 2017 Accepted: 29 May 2018

Published online: 25 June 2018

\section{References}

1. Becher P, Avalos Ramirez R, Orlich M, Cedillo Rosales S, Konig M, Schweizer $\mathrm{M}$, Stalder $\mathrm{H}$, et al. Genetic and antigenic characterization of novel pestivirus genotypes: implications for classification. Virology. 2003;311:96-104.
2. Wu HX, Wang JF, Zhang CY, Fu LZ, Pan ZS, Wang N, et al. Attenuated lapinized chinese strain of classical swine fever virus: complete nucleotide sequence and character of 3'-noncoding region. Virus Genes. 2001;23:69-76.

3. Meyers G, Thiel HJ. Molecular characterization of pestiviruses. Adv Virus Res. 1996:47:53-118.

4. Thiel HJ, Stark R, Weiland E, Rumenapf T, Meyers G. Hog cholera virus: molecular composition of virions from a pestivirus. J Virol. 1991;65:4705-12.

5. Lowings $P$, Ibata G, Needham J, Paton D. Classical swine fever virus diversity and evolution. J Gen Virol. 1996;77(Pt 6):1311-21.

6. Paton DJ, McGoldrick A, Greiser-Wilke I, Parchariyanon S, Song JY, Liou PP, et al. Genetic typing of classical swine fever virus. Vet Microbiol. 2000;73:137-57.

7. Deng MC, Huang CC, Huang TS, Chang CY, Lin YJ, Chien MS, et al. Phylogenetic analysis of classical swine fever virus isolated from Taiwan. Vet Microbiol. 2005;106:187-93.

8. Pan CH, Jong MH, Huang TS, Liu HF, Lin SY, Lai SS. Phylogenetic analysis of classical swine fever virus in Taiwan. Arch Virol. 2005;150:1101-19.

9. Gong W, Wu J, Lu Z, Zhang L, Qin S, Chen F, et al. Genetic diversity of subgenotype 2.1 isolates of classical swine fever virus. Infect Genet Evol. 2016;41:218-26.

10. Tu C, Lu Z, Li H, Yu X, Liu X, Li Y, et al. Phylogenetic comparison of classical swine fever virus in China. Virus Res. 2001;81:29-37.

11. Shen H, Pei J, Bai J, Zhao M, Ju C, Yi L, et al. Genetic diversity and positive selection analysis of classical swine fever virus isolates in South China. Virus Genes. 2011;43:234-42.

12. Chen N, Hu H, Zhang Z, Shuai J, Jiang L, Fang W. Genetic diversity of the envelope glycoprotein E2 of classical swine fever virus: recent isolates branched away from historical and vaccine strains. Vet Microbiol. 2008;127:286-99.

13. Chen N, Tong C, Li D, Wan J, Yuan X, Li X, et al. Antigenic analysis of classical swine fever virus E2 glycoprotein using pig antibodies identifies residues contributing to antigenic variation of the vaccine C-strain and group 2 strains circulating in China. Virol J. 2010;7:378.

14. Leng $\mathrm{CL}$, Zhang $\mathrm{HL}$, Kan YC, Yao LG, Li ML, Zhai HY, et al. Characterisation of newly emerged isolates of classical swine fever virus in China, 2014-2015. J Vet Res. 2017;61:9.

15. Jiang DL, Gong WJ, Li RC, Liu GH, Hu YF, Ge M, et al. Phylogenetic analysis using E2 gene of classical swine fever virus reveals a new subgenotype in China. Infect Genet Evol. 2013;17:231-8.

16. Postel A, Schmeiser S, Perera CL, Rodriguez LJ, Frias-Lepoureau MT, Becher P. Classical swine fever virus isolates from Cuba form a new subgenotype 1. 4. Vet Microbiol. 2013;161:334-8.

17. Zhang H, Leng C, Feng L, Zhai H, Chen J, Liu C, et al. A new subgenotype 2 . 1d isolates of classical swine fever virus in China, 2014. Infect Genet Evol. 2015;34:94-105

18. Tamura K, Peterson D, Peterson N, Stecher G, Nei M, Kumar S. MEGA5: molecular evolutionary genetics analysis using maximum likelihood, evolutionary distance, and maximum parsimony methods. Mol Biol Evol. 2011:28:2731-9.

19. Edgar RC. MUSCLE: a multiple sequence alignment method with reduced time and space Complexity. BMC bioinformatics. 2004:5:113.

20. Mittelholzer C, Moser C, Tratschin JD, Hofmann MA. Analysis of classical swine fever virus replication kinetics allows differentiation of highly virulent from avirulent strains. Vet Microbiol. 2000;74:293-308.

21. Ferrari M, Gualandi GL, Corradi A, Monaci C, Romanelli MG, Tosi G, et al. Experimental infection of pigs with a thymidine kinase negative strain of pseudorabies virus. Comp Immunol Microbiol Infect Dis. 1998;21:291-303.

22. Sur JH, Cooper VL, Galeota JA, Hesse RA, Doster AR, Osorio FA. In vivo detection of porcine reproductive and respiratory syndrome virus RNA by in situ hybridization at different times postinfection. J Clin Microbiol. 1996;34:2280-6.

23. Edwards S, Fukusho A, Lefevre PC, Lipowski A, Pejsak Z, Roehe P, et al. Classical swine fever: the global situation. Vet Microbiol. 2000;73:103-19.

24. Luo Y, Li S, Sun Y, Qiu HJ. Classical swine fever in China: a minireview. Vet Microbiol. 2014;172:1-6.

25. Hu D, Lv L, Gu J, Chen T, Xiao Y, Liu S. Genetic diversity and positive selection analysis of classical swine fever virus envelope protein gene E2 in East China under C-strain vaccination. Front Microbiol. 2016;7:85.

26. Blacksell SD, Khounsy S, Boyle DB, Greiser-Wilke I, Gleeson LJ, Westbury HA, et al. Phylogenetic analysis of the E2 gene of classical swine fever viruses from Lao PDR. Virus Res. 2004;104:87-92.

27. Sarma DK, Mishra N, Vilcek S, Rajukumar K, Behera SP, Nema RK, et al. Phylogenetic analysis of recent classical swine fever virus (CSFV) isolates from Assam, India. Comp Immunol Microbiol Infect Dis. 2011;34:11-5. 
28. Postel A, Schmeiser S, Bernau J, Meindl-Boehmer A, Pridotkas G, Dirbakova

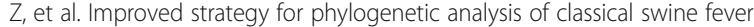
virus based on full-length E2 encoding sequences. Vet Res. 2012;43:50.

29. Li X, Xu Z, He Y, Yao Q, Zhang K, Jin M, et al. Genome comparison of a novel classical swine fever virus isolated in China in 2004 with other CSFV strains. Virus Genes. 2006;33:133-42.

30. Shen HY, Wang JY, Dong XY, Zhao MQ, Kang Y, Li YG, et al. Genome and molecular characterization of a CSFV strain isolated from a CSF outbreak in South China. Intervirology. 2013;56:122-33.

31. Luo TR, Liao SH, Wu XS, Feng L, Yuan ZX, Li H, et al. Phylogenetic analysis of the E2 gene of classical swine fever virus from the Guangxi Province of southern China. Virus Genes. 2011;42:347-54

32. Hsu WL, Chen CL, Huang SW, Wu CC, Chen IH, Nadar M, et al. The untranslated regions of classic swine fever virus RNA trigger apoptosis. PLoS One. 2014:9:e88863.

33. Fletcher SP, Jackson RJ. Pestivirus internal ribosome entry site (IRES) structure and function: elements in the $5^{\prime}$ untranslated region important for IRES function. J Virol. 2002;76:5024-33.

34. Wang Y, Wang Q, Lu X, Zhang C, Fan X, Pan Z, et al. 12-nt insertion in 3' untranslated region leads to attenuation of classic swine fever virus and protects host against lethal challenge. Virology. 2008;374:390-8.

35. Coronado L, Liniger M, Munoz-Gonzalez S, Postel A, Perez LJ, Perez-Simo M, et al. Novel poly-uridine insertion in the $3^{\prime} U T R$ and E2 amino acid substitutions in a low virulent classical swine fever virus. Vet Microbiol. 2017; 201:103-12.

36. Chen Y, Xiao J, Xiao J, Sheng C, Wang J, Jia L, et al. Classical swine fever virus NS5A regulates viral RNA replication through binding to NS5B and 3'UTR. Virology. 2012;432:376-88.

37. Li S, Feng S, Wang JH, He WR, Qin HY, Dong $H$, et al. eEF1A interacts with the NS5A protein and inhibits the growth of classical swine fever virus. Viruses. 2015;7:4563-81.

38. Sheng C, Chen Y, Xiao J, Xiao J, Wang J, Li G, et al. Classical swine fever virus NS5A protein interacts with 3'-untranslated region and regulates viral RNA synthesis. Virus Res. 2012;163:636-43.

39. Risatti GR, Borca MV, Kutish GF, Lu Z, Holinka LG, French RA, et al. The E2 glycoprotein of classical swine fever virus is a virulence determinant in swine. J Virol. 2005:79:3787-96.

40. van Rijn PA, Miedema GK, Wensvoort G, van Gennip HG, Moormann RJ. Antigenic structure of envelope glycoprotein E1 of hog cholera virus. J Virol. 1994;68:3934-42.

41. Dong XN, Chen YH. Marker vaccine strategies and candidate CSFV marker vaccines. Vaccine. 2007:25:205-30

42. Leifer I, Hoeper D, Blome S, Beer M, Ruggli N. Clustering of classical swine fever virus isolates by codon pair bias. BMC Res notes. 2011;4:521.

43. Floegel-Niesmann G, Blome S, Gerss-Dulmer H, Bunzenthal C, Moennig V. Virulence of classical swine fever virus isolates from Europe and other areas during 1996 until 2007. Vet Microbiol. 2009;139:165-9.

44. Luo Y, Ji S, Liu Y, Lei JL, Xia SL, Wang Y. Isolation and characterization of a moderately virulent classical swine fever virus emerging in China. Transbound Emerg Dis. 2017:64:1848-57.

\section{Ready to submit your research? Choose BMC and benefit from:}

- fast, convenient online submission

- thorough peer review by experienced researchers in your field

- rapid publication on acceptance

- support for research data, including large and complex data types

- gold Open Access which fosters wider collaboration and increased citations

- maximum visibility for your research: over $100 \mathrm{M}$ website views per year

At BMC, research is always in progress.

Learn more biomedcentral.com/submissions 